\title{
Rab-KAMS: A Reproducible Knowledge Management System with Visualization for Preserving Rabbit Farming and Production Knowledge
}

\author{
Temitayo Matthew Fagbola ${ }^{1}$, Surendra Colin Thakur $^{2}$, Oludayo Olugbara ${ }^{3}$ \\ ICT and Society Research Group, Durban University of Technology, \\ Durban 4000, South Africa
}

\begin{abstract}
The sudden rise in rural-to-urban migration has been a key challenge threatening food security and most especially the survival of Rabbit Farming and Production (RFP) in Sub-Saharan Africa. Currently, significant knowledge of RFP is going into extinction as evident by the drastic fall in commercial rabbit farming and production indices. Hence, the need for a system to proactively preserve RFP knowledge for future potential farmers cannot be overemphasized. To this end, knowledge archiving and management are key concepts of ensuring long-term digital storage of conceptual blueprints and specifications of systems, methods and frameworks with capacity for future updates while making such information readily accessible to relevant stakeholders on demand. Therefore, a reproducible Rabbit production' Knowledge Archiving and Management System (Rab-KAMS) is developed in this paper. A 3-staged approach was adopted to develop the Rab-KAMS. This include a knowledge gathering and conceptualization stage; a knowledge revision stage to validate the authenticity and relevance of the gathered knowledge for its intended purpose and a prototype design stage adopting the use of unified modelling language conceptual workflows, ontology graphs and frame system. For seamless accessibility and ubiquitous purposes, the design was implemented into a mobile application having interactive end-users' interfaces developed using XML and Java in Android 3.0.2 Studio development environment while adopting the $V$-shaped software development model. The qualitative evaluation results obtained for Rab-KAMS based on users' rating and reviews indicate a high level of acceptability and reliability by the users. It also indicates that relevant RFP knowledge were correctly captured and provided in a userfriendly manner. The developed Rab-KAMS could offer seamless acquisition, representation, organization and mining of new and existing verified knowledge about RFP and in turn contributing to food security.
\end{abstract}

Keywords-Knowledge_archiving; knowledge_management; mobile design; starUML; protégé-OWL; rabbit production; reproducibility; ubiquitous ontology

\section{INTRODUCTION}

Knowledge is a conspicuously valuable resource to a vast number of sectors and has been a prominent basis for successful accomplishment due to its close connection and peculiarity with time. Knowledge enacted an influence which created a breach of having to recreate or reinvent concepts, hereby bringing time conservation to limelight [1]. More importantly than knowledge itself, is its conservation and management. Instances such as increased domain complexity, market volatility, employee turnover, migrations and employment preference have over time intensified emphasis laid on the importance to efficiently and effectively manage knowledge, and make such knowledge readily available when needed [2]. When knowledge is not being carefully and properly managed, such knowledge goes extinct with reference to time and might require a regeneration from the scratch if the situation to apply or make use of such knowledge arises.

Arisha and Ragab [1] articulated that the probable loss or extinction of knowledge tends to increase with regards to workforce mobility and layoffs, which in turn hampers a system's overall success and achievement. Consequently, archives and archiving processes are liable to provide necessary infrastructure for long-term safeguard of knowledge which entails values beyond the original purpose of its creation should the author not exist anymore [3]. In the same vein, one key purpose of digital archiving of data is to foster knowledge exchange among a number of disparate people, organizations and communities as stressed by Christine et al. [4] with strong potential for data reusability and sharing. Schweizerische [5] stated that reusability and sharing are essential characteristics of archiving and can be depicted by easy location, retrieval, presentation and inference of such information. Reusability and sharing amongst many other archiving characteristics are purely achievable through an important concept known as knowledge management [6].

Knowledge management refers to the transmogrification of information and intellectual assets into assets of enduring values [7]. It involves a number of activities that aids the discovery, selection, organization, dissemination and transfer of grossly important skills, expertise and carefully refined information necessary for strategic planning, making decisions and any other activity within an organization [8], [9]. It aids the fulfillment of organizational objectives through the development of knowledge assets and processes guiding the planning and decisions of organizational actions [10], [11]. Thus, knowledge management is highly important for the conservation of valuable organizational knowledge, 
advancement of organizational activities and improved competitive edge in a business environment [12]. When dealing with knowledge management and representation, employing ontology, a modeling paradigm for organizing concepts related to knowledge and semantics, is practical to achieving success [13]. Giovanni et al. [14] iterated the vivid usefulness of ontologies in terms of conceptual representation, provision of support for knowledge discovery, extraction and integration with visualization support for representing complex systems and processes.

In the past few decades, agriculture began to face a mind rattling knowledge loss and probable extinction of valuable details that were peculiar to achieving success within its domain due to civilization and a sudden rise in rural-urban migrations [15]-[18]. In fact, considering the point that agriculture helps to meet the basic needs of human and their civilization by providing food, clothing, shelters, medicine and recreation implies that agriculture is one of the most critical enterprise in the world. Hence, preservation of knowledge about agricultural practices is very essential in a bid to salvage knowledge loss and extinction that can result into an alarming state of the nation. As evident, farming and production of lesscommonly-bred animals like rabbits are now rarely practiced due to a larger percentage of individuals vying to mastermind production of relatively common animals such as fowls, pigs and cattle while others have abandoned such farming practices for white-collar jobs as civilization trends grow more [19], [20].

This in turn has led to a drastic drop in the production level of rabbit [16]. It is becoming a reality that such noble rabbit rearing profession, a business investment with huge potential of aiding socio-economic growth and food security [21], having consequently gained popularity as a veritable source of alleviating protein deficiencies [22], would go into extinction in no time. Agricultural knowledge, especially those associated with the production of rabbits, can be practically and consciously sustained and/or prevented from loss or attenuation of any form through archiving and effective management of its knowledge.

Representation and archiving of knowledge for inference, future adaptation and further analysis is an important aspect of artificial intelligence. Peng et al. [23] discussed how knowledge representation and management can be visualized from the academic discipline point of view, its characteristics and performance towards sustaining a knowledge domain. To formally portray this representation of knowledge, ontologies are employed. Ontology, defined as detailed description of a conceptual idea, identifies the various links between concepts [24]. Ontologies have been proven to be of great importance to agriculture because of its ease of interoperability with disparate data sources [25]. Within the agricultural domain, ontologies assist individuals and stakeholders to make appropriate practical choices with the aid of available facts. Furthermore, unclassified class divisions are identified and properly classified with the use of ontologies. This way, components can be monitored, arranged and correlated to discover possible relationships and influences. According to Ruban et al. [26], efficient and accurate retrieval of information has become much more important globally.
Currently, domain ontology functions as the lifeline of the semantic web by making available formal conceptualization and vocabularies of the provided domain to facilitate information sharing and exchange.

Suresh et al. [27] identified several numbers of steps towards the development of ontological system (AgriNepalData) for data access and integration aimed at improving farming operations' effectiveness. These include extraction, storage and querying, manual revision and authoring, district, interlinking, classification and enrichment, evolution and repair, search and browsing. Fagbola et al. [25] developed RROVT, a generalized visualization tool for systems and processes of any domain aided by semanticallyinterpretable web technologies. Aunur-Rofiq, et al. [28] proposed an ontology-driven food transformation processes involving winemaking for the purpose of knowledge containment and sharing. Mutao and Yong [29] presented a centralized system to manage, archive and share scientific data in eco-hydrological research. Daiyi et al. [13] presented a composite representation method embodying both task and domain ontologies on crop cultivation standards. The authors investigated, identified, analyzed and archived good agricultural practices into portable ontologies.

Han [30] proposed an interpretable and semanticallyexpressive knowledge graph for unsupervised structures in a two-stage hierarchical representation process. Mohammed and Danciulescu [24] developed novel interfaces with markup frameworks to represent knowledge generated by processing systems. Rashmi and Neha [31] used reasoning mechanism and domain understanding to represent knowledge in artificial intelligence. Using the knowledge acquired from behavioral changes in animals, Vijay and Sunitha [32] developed a knowledge expressive semantic ontology for animal disaster prediction such that behavioral changes exhibited by animals are conceptually presented. Sabina and Leonids [33] discussed how knowledge representation models' compliance with set requirements specification can be measured and the most appropriate knowledge representation model chosen. Didem et al. [34] developed a knowledge representation model for cyber-physically-automated warehouses that could assist with monitoring the performance level of each component of the cyber-physical system. Sarika and Sanju [35] presented a prototype ontology tool-based knowledge representation approach with focus on speed and efficiency of knowledge retrieval. The authors also provided exposition on some recent ontology methodologies and tools. Aaron and Andreas [36] applied natural language processing pedagogies to represent the knowledge of the requirements documents domain with the aim of presenting a number of natural language requirements in the form of knowledge descriptive graphs.

However, a knowledge archiving and management system to preserve, sustain and ensure reproducibility of rabbit farming practices should the farmers, experts and professionals exist no more is highly desirable and is currently an open problem as no such system exists. Therefore in this paper, a mobile-oriented and reproducible knowledge archiving and management system for rabbit farming and production (Rab-KAMS) is developed. The mobile platform is considered for reasons including seamless reusability, easy 
accessibility and sharing, ubiquity, portability and interpretability of rabbit production knowledge. This work spans across farming and production activities of rabbit within Nigeria and can be adopted in regions where similar associated factors are considered equivalent. Experts knowledge elucidated and used in this study are valid and relevant to the farming and production of rabbit as at when this study was conducted. The key concepts of Rab-KAMS are those bothering on infrastructures, nutrition, management and value concepts of RFP. Invariably, Rab-KAMS serves as a knowledge hub for rabbit production strategies and best farming methods.

\section{MATERIALS AND METHOD}

The research questions and the definitive stepwise developmental approach to Rab-KAMS are presented in this section.

\section{A. Research Questions}

1) How can the knowledge of rabbit production and farming in South Western part of Nigeria be sustained and preserved over time against extinction?

2) How can the preserved knowledge be well managed, made ubiquitous and accessible to end-users and interest groups?

3) How can the knowledge be sustained to allow for reusability and sharing over time?

\section{B. Rab-KAMS Stepwise Developmental Approach}

In this section, a highlight of the specific steps followed while developing Rab-KAMS is presented. These include:

1) Knowledge gathering on rabbit production and rearing a. Infrastructure

i. Housing-How the houses for rearing rabbits should be constructed.

ii. Environment-Required environmental conditions for proper production.

iii. Equipment-Tools and things needed for hitch free rabbit production.

\section{b. Nutrition}

i. Feeding-Feeding requirements of rabbits.

ii. Feeding System-Best feeding practices to ensure smooth production.

\section{c. Management}

i. Pathology-The various diseases that affects rabbits

ii. Stock-Specific qualities to look out for in selection of rabbit breeds

iii. Reproduction

- Mating-Procedure for copulation of male and female rabbits

- Pregnancy-Determination and care for pregnant rabbits
- Kindling-Delivery and care for young rabbits

- Weaning and Sexing-Best practices on separating doe from the litters and identification of young rabbits' gender.

d. Values

1) Cotton and skin production

2) Meat production

i. Revision of Extracted Knowledge (validation and verification)

ii. Design of a knowledge archival and management system for rabbit farming and production

iii. Implementation of the design in (iii) above following a $\mathrm{V}$-shaped software life cycle development model

\section{Knowledge Gathering on Rabbit Production and Rearing}

From the wide domain of agriculture, distinguished experts in the subdomain of rabbit production have over the years been able to put together adequate knowledge to ensure proficient production and farming of rabbits. These expert knowledge relating to rabbit farming were identified from numerous experts' experiences and sufficient knowledge void of noise and propagandas were extracted to build the knowledge-base. More specifically, knowledge regarding infrastructure (housing, environment and equipment), nutrition (feeding requirements and feeding system), management (pathology, stock and reproduction) and values (cotton, skin and meat production) that characterize rabbit farming and production were gathered.

\section{Revision of Extracted Knowledge}

Since knowledge improves on a daily basis, verification of the obtained knowledge becomes necessary. The experts were consulted with the final corpus of elicited knowledge for validation and verification purposes. After an extensive knowledge analysis was conducted, the extracted and retrieved knowledge were revised so as to ascertain their validity and relevance with the current trends of rabbit farming and production. Obsolete knowledge were manually sorted and excluded from the knowledge base while a limited other incomplete knowledge were cushioned with the necessary update(s).

\section{E. Design of the Mobile-Oriented Knowledge Management Archiving System for Rabbit Production and Farming Practice}

In this section, the conceptual designs for the Rab-KMAS are presented. These include the Use Case diagram, class model diagram, data flow diagram, activity diagram, sequence diagram and flow chart representation using StarUml 5.0 while the ontology graph for visualization was developed using Protégé 5.2 [37]-[40]. However, UML was employed to make the description of the complex processes of rabbit production and farming easier to analyze, and also to aid quick, detailed and explicit visualization / description of activities, relationships and objects. UML simply helps to represent static and dynamic systems and processes conceptually [33],[41],[42]. 
F. Class Model Diagram for the Mobile Rab-KAMS (Rabbit Farming and Production Knowledge Archiving and Management System)

In an object-oriented context, classes of the rabbit production knowledge archiving and management system were modeled as presented in Fig. 1. Class diagram identifies objects in a system and establishes the common interrelationship (for example, cardinality and inheritance characteristics) among them [37], [40]. In the model, the inference engine class infers what knowledge best fits the user's query by searching through the knowledge available in the knowledge base.

\section{G. UML use Cases Design for the user of the Developed Archive System}

Use cases diagrams allow a coarse-grain conceptual representation of interactions of objects in processes and / or systems in units [43], [44]. The Use case diagram presented in Fig. 2 describes specifically how the actor (rabbit farmer) will relate with the developed system.

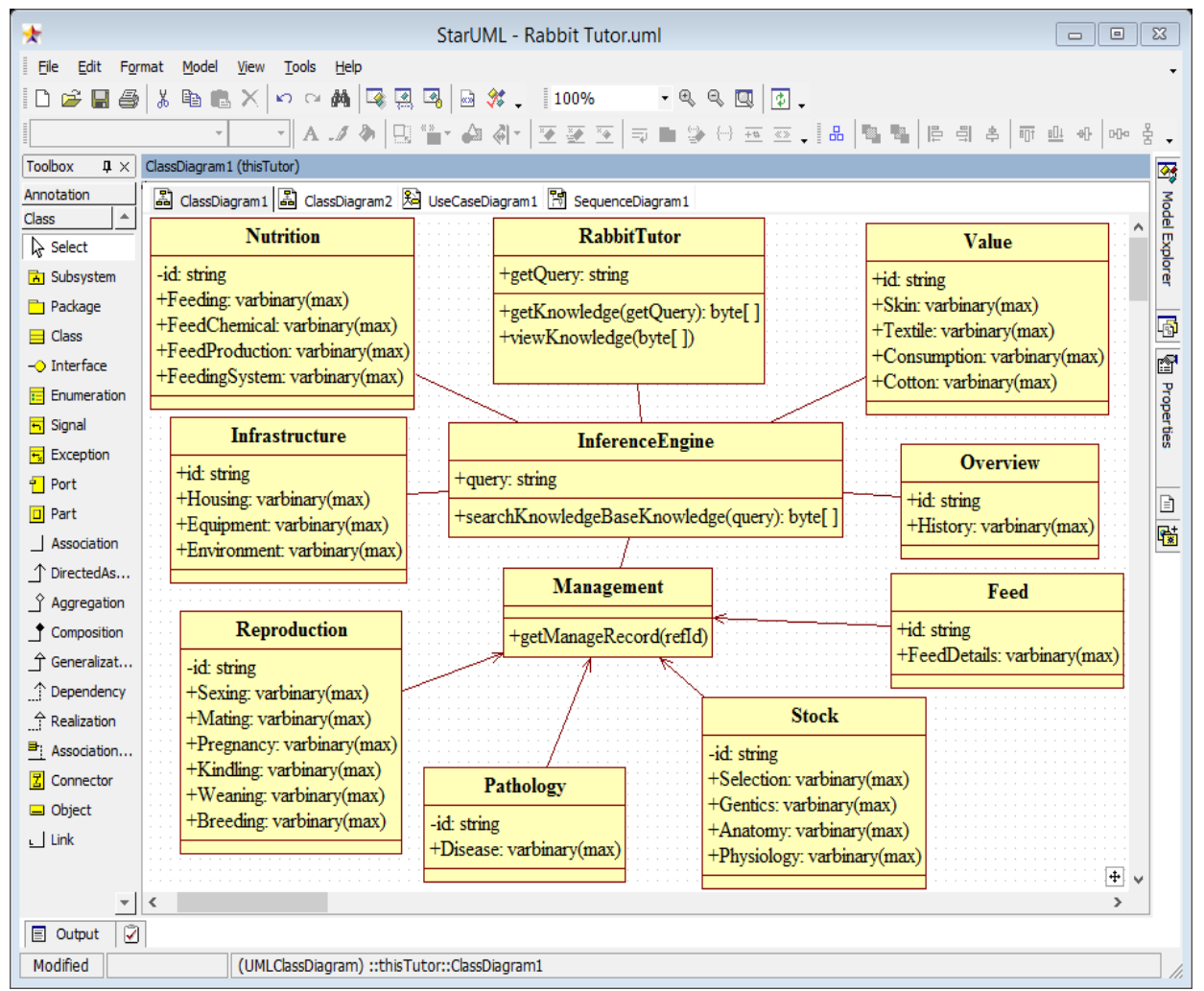

Fig. 1. Class Diagram for the Rabbit Production Knowledge Archiving and Management.

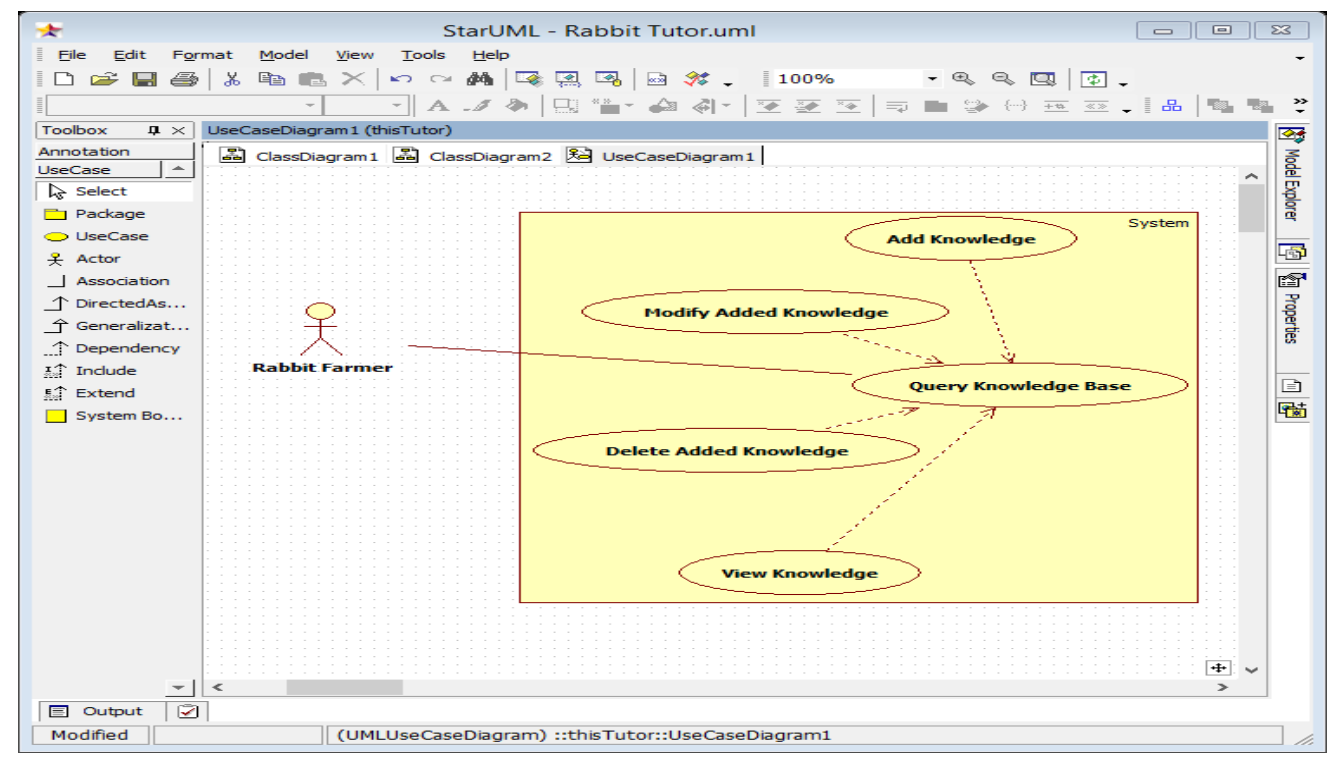

Fig. 2. Use Case Diagram of the Rabbit Production Knowledge Archiving and Management. 


\section{H. Rabbit Archive Activity and Sequence Diagram}

Activity diagram shown in Fig. 3 was used to illustrate the actionable features of the system. This diagram helps to establish the line of execution of internal processes among a number of objects in a system more easily when processing an activity [43]. It also depicts how the system processes flow from one level of activity to another in the system. Sequence diagram presented in Fig. 4 describes object interactions arranged in time sequence. Sequence diagram often presents concurrent flow of internal processes and how they are going to be executed.

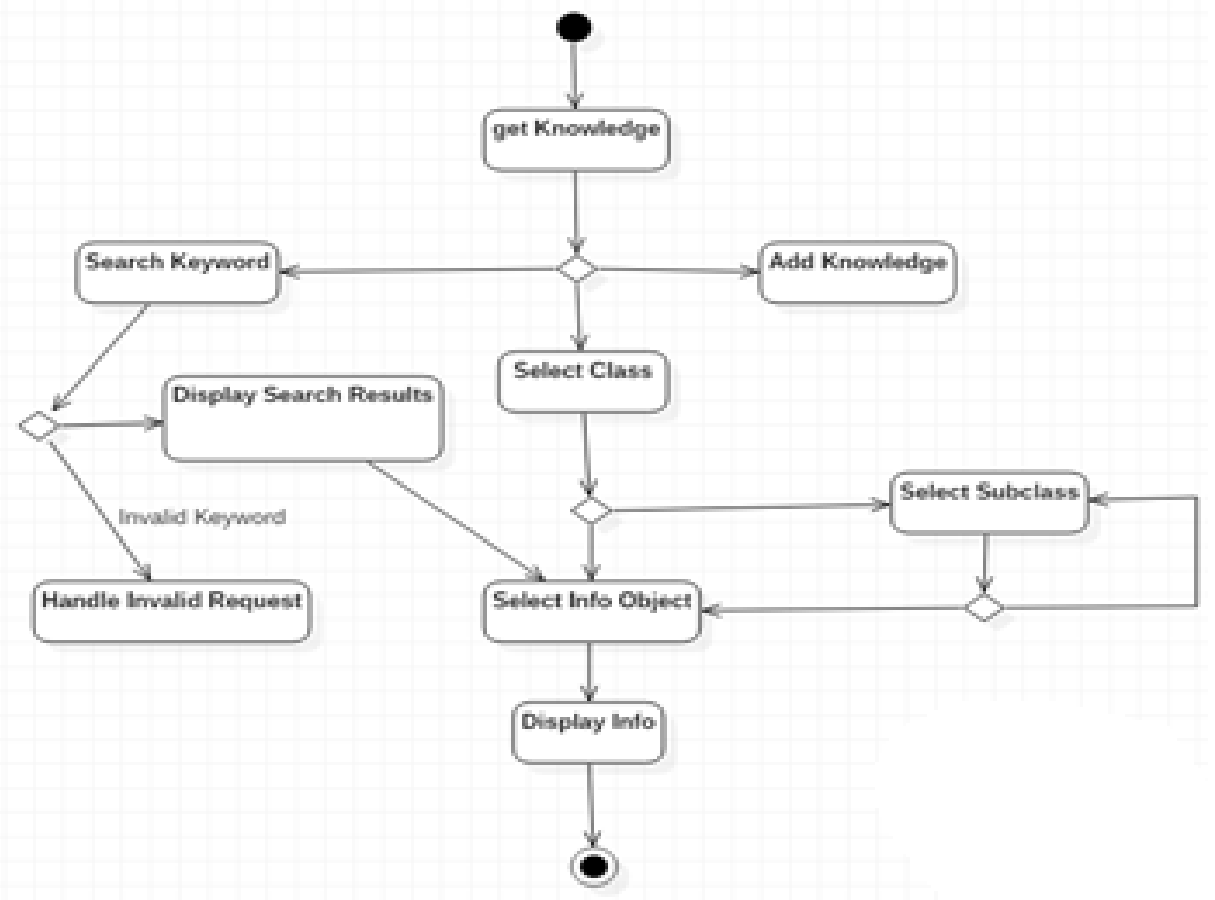

Fig. 3. Activity Diagram of the Developed Archiving and Management System.

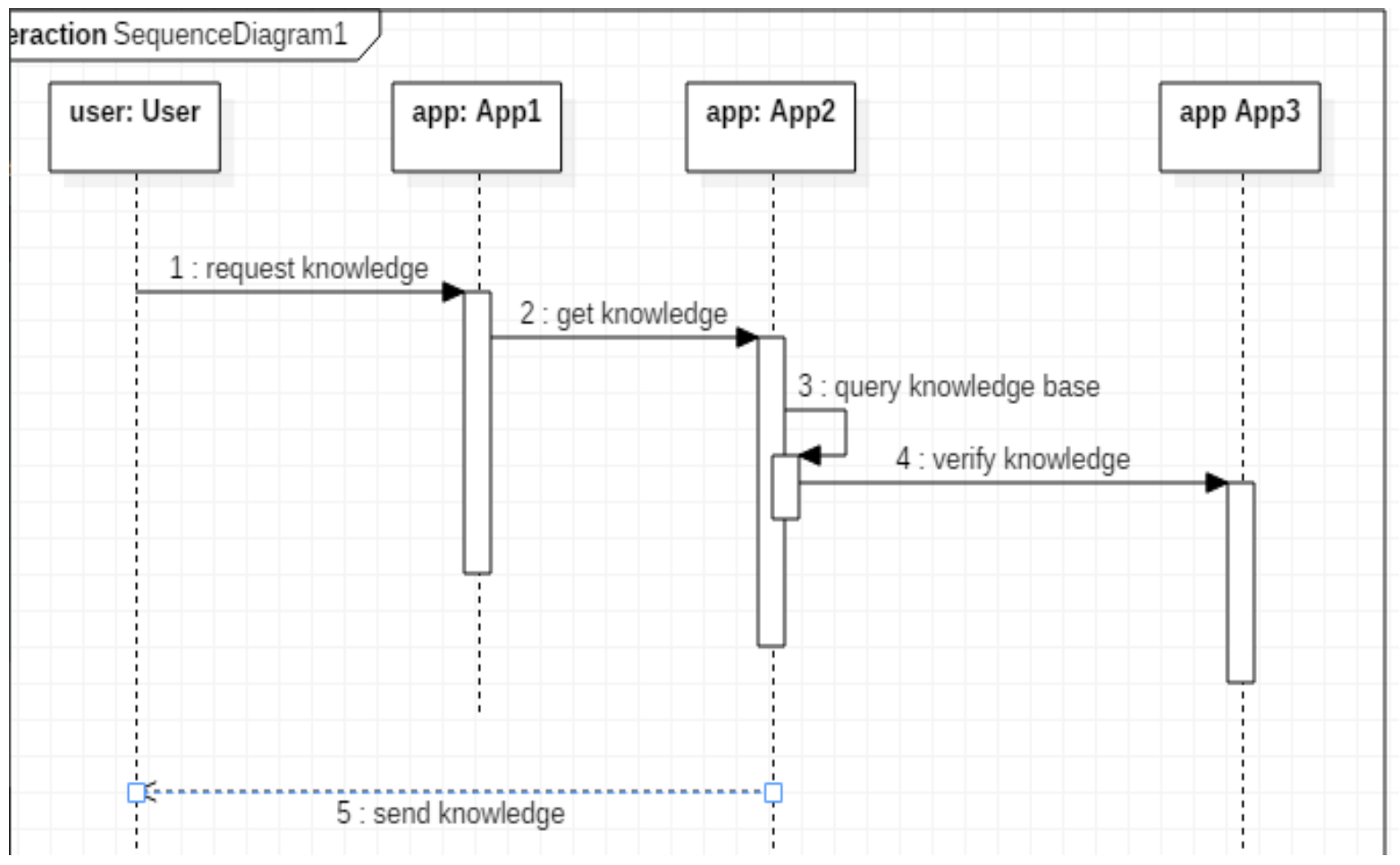

Fig. 4. Sequence Diagram of the Developed Archiving and Management System. 


\section{Rabbit Archive Ontology Graph Representation with Visualization}

The ontology of rabbit rearing and production which was designed using Protégé 5.2 is as presented in Fig. 5. The classes and subclasses represented in the ontology are regarded by experts in the field as reliable for the rearing and production of rabbit from the scratch to the final stages of production. The subclasses are such that each has a reference to the class that hosts it and with other subclasses within its domain under the context of the propeties of their class.

\section{J. Rabbit Archiving Frame Systems}

In a more clearer perspective, a frame system for the rabbit production archiving and knowledge management system is presented in Fig. 6 to further illustrate the relationships amongst the classes. The frame system described the "a kind of" (ako) and "is a" (is_a) relationship amongst the objects.
Kindly refer to the work of Nazaruks and Osis [45] for an explicit discussion on frame system design.

\section{K. Flow Model Designs for the Implementation of the Rabbit Production Knowledge Archiving and Management}

The developed rabbit production knowledge archiving and management system design was implemented within an Android 3.0.2 Studio environment, using XML for the design of the Graphical User Interface (GUI) and Java for the logic that unifies the GUI with the underlying implementations.

The algorithm of the rabbit production knowledge archiving and management system is as described in the flowchart presented in Fig. 7. The flowchart describes the implementation algorithm of the archiving system. Users create queries with the aid of the graphical user interface, this query is sent to the inference engine which sorts the requests and eventually presents the required information.

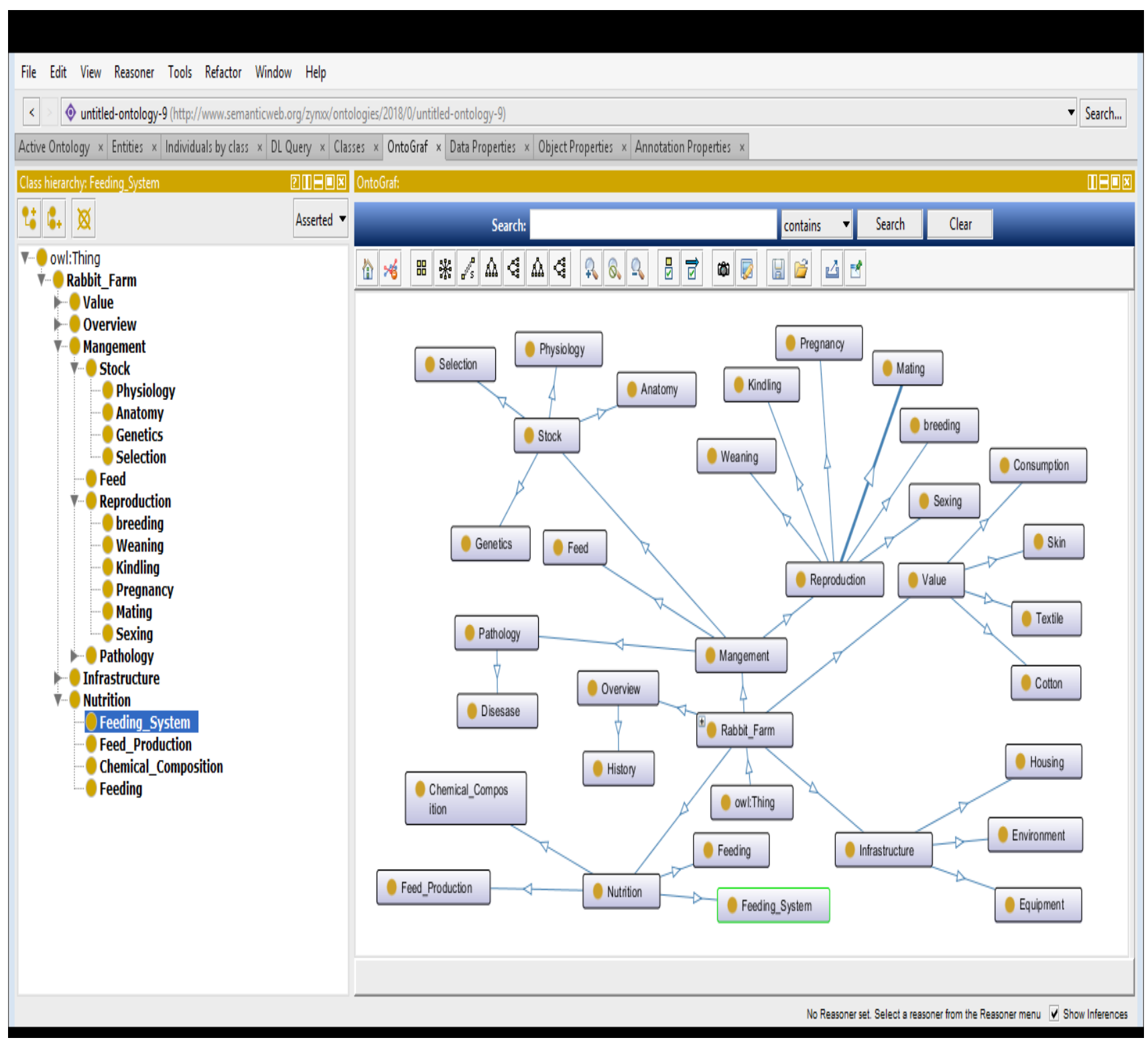

Fig. 5. Domain Ontology Representation for Rabbit Farming Knowledge with Protégé 5.2. 


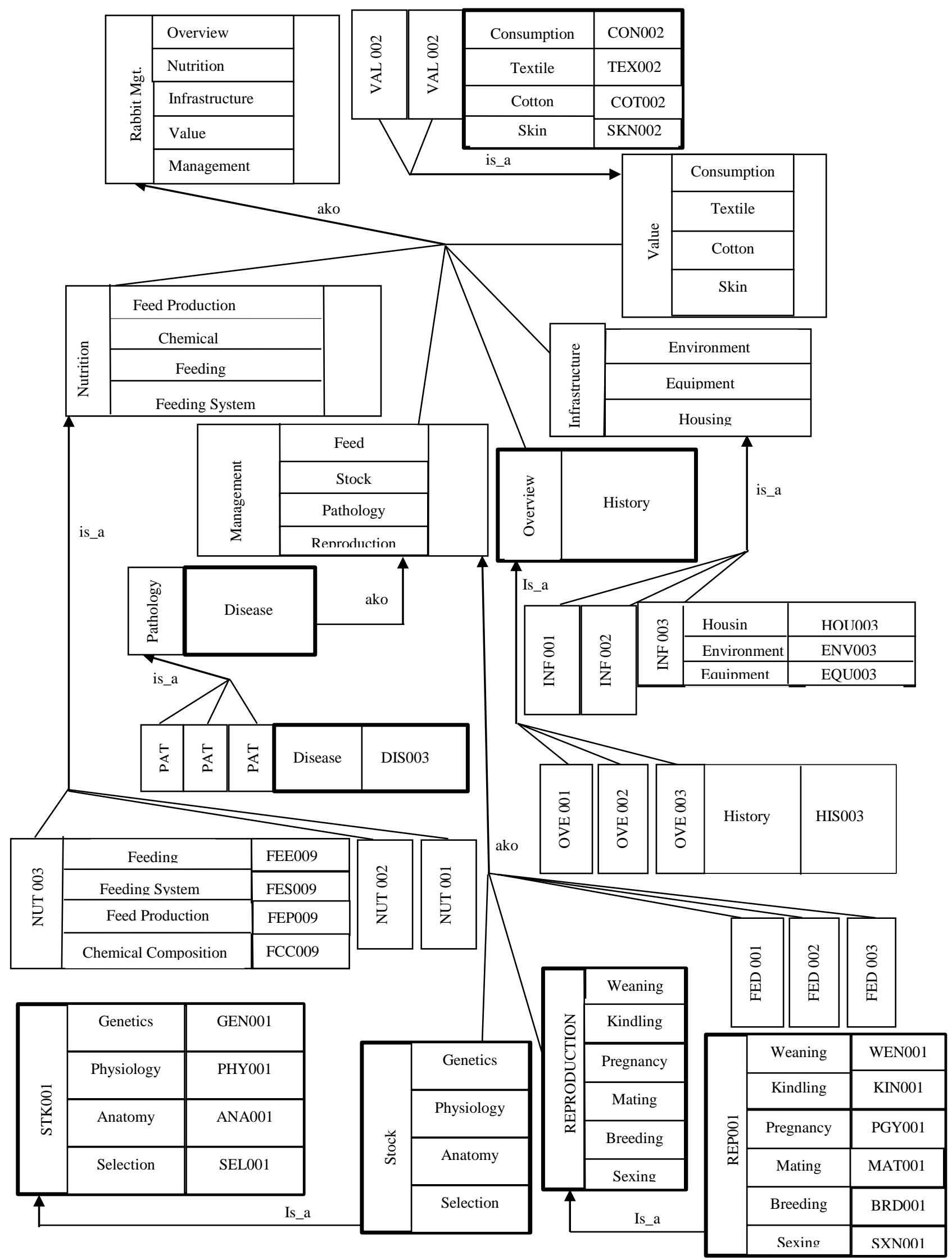

Fig. 6. Frame System for Rabbit Production Knowledge Archiving and Management System Ontology. 


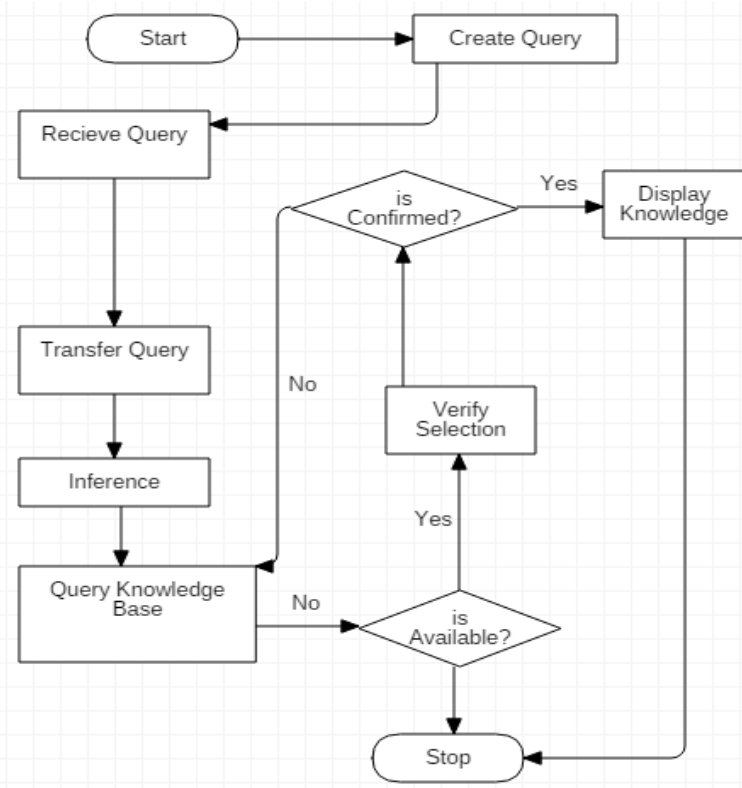

Fig. 7. Rabbit Production Knowledge Archiving and Management Implementation Flowchart.

\section{RESULTS AND DISCUSSION}

The implementation and qualitative evaluation results for the developed Mobile Rab-KAMS is presented in this section. A sample implementation code for the development of the abKAMS application in an android development environment using Java programming language is presented in Fig. 8. The interface of the mobile application was developed using XML and Java.

\section{A. Implementation Functional Interfaces for the Mobile Rab- KAMS}

Rabbit farmers or prospective ones can select to learn from any of the subclasses presented in the various classes contained in the home of the rabbit production knowledge archiving and management system. Each of these subclasses entails information related to their various titles a depicted in Fig. 9. The interface presented in Fig. 10 depicts the interface of subclasses and specific subclass information using buttons and dropdowns. These class implementations lead to information which specifically address what the users (rabbit farmers or prospective ones) need to know in that domain or subdomain. Users (rabbit farmers and prospective) of the rabbit production knowledge archiving and management system learns about what is needed and required of them to ensure a successful start-up and conclusion from the specific subclass information interface.

In Fig. 11, the link that leads to the knowledge inclusion interface and the knowledge inclusion interface itself is presented. User can make use of the "add new" button or simply click on the "+" button (at the bottom-right corner of the home interface) to channel up the knowledge inclusion interface. Users have to select the domain or subdomain where the knowledge to be included belongs as depicted in Fig. 12. If the knowledge to be included for offline usage includes images, the users can include these images by either taking a photograph or uploading from the user's phone gallery. Therefore, users can include additional information from extension workers, heuristic approaches or other means. The knowledge is saved into memory through the "envelope" icon present at the bottom-right corner of the knowledge inclusion interface.

To enhance easy access to important details and information, a search mechanism was put in place as presented in Fig. 13. Keywords are typed into the textbox and a list of related documents is presented just as shown in Fig. 14. The most relevant information to prospective users can then be selected from this list and viewed.

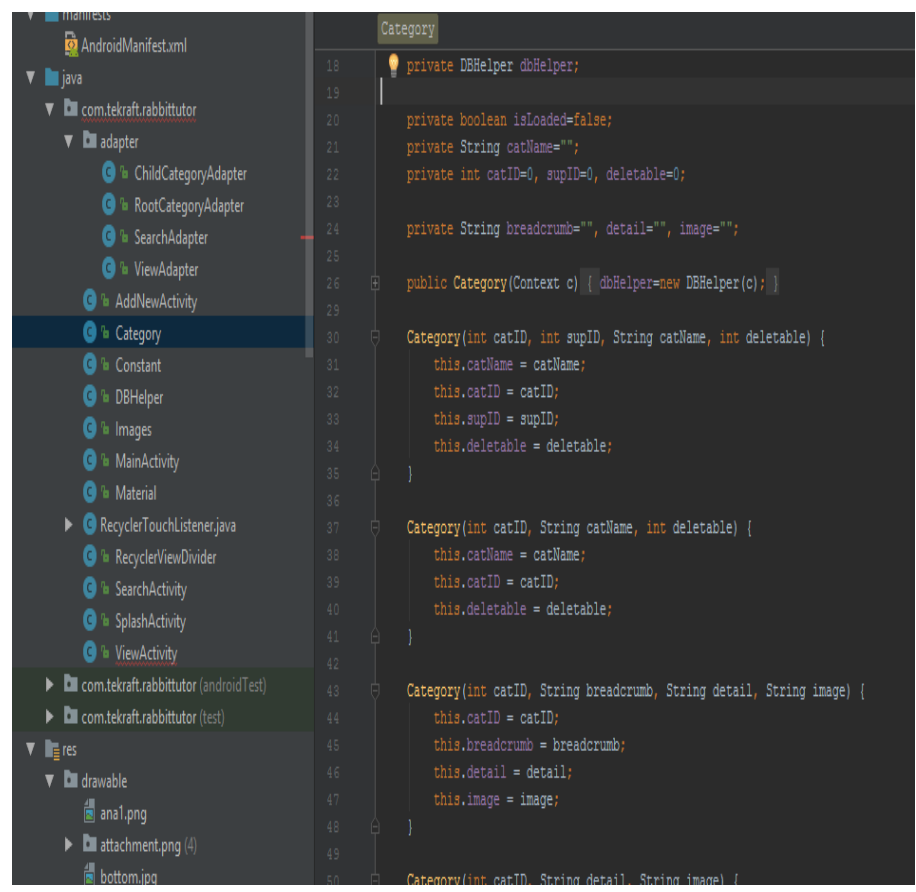

Fig. 8. Screenshot of Android Mobile Code Snippet for Rab-KAMS.
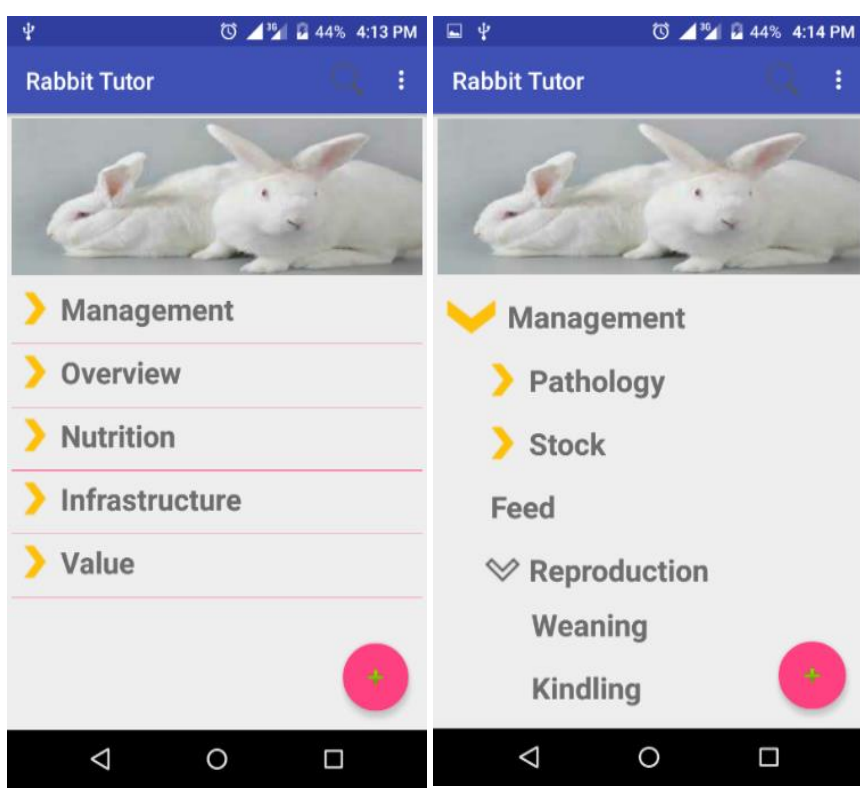

Management

Pathology

Stock

Feed

$\checkmark$ Reproduction

Weaning

Kindling

\section{$\triangleleft \quad \bigcirc \quad \square$}

Fig. 9. Interfaces of Various Classes and Subclasses of the Rab-KAMS Knowledge. 


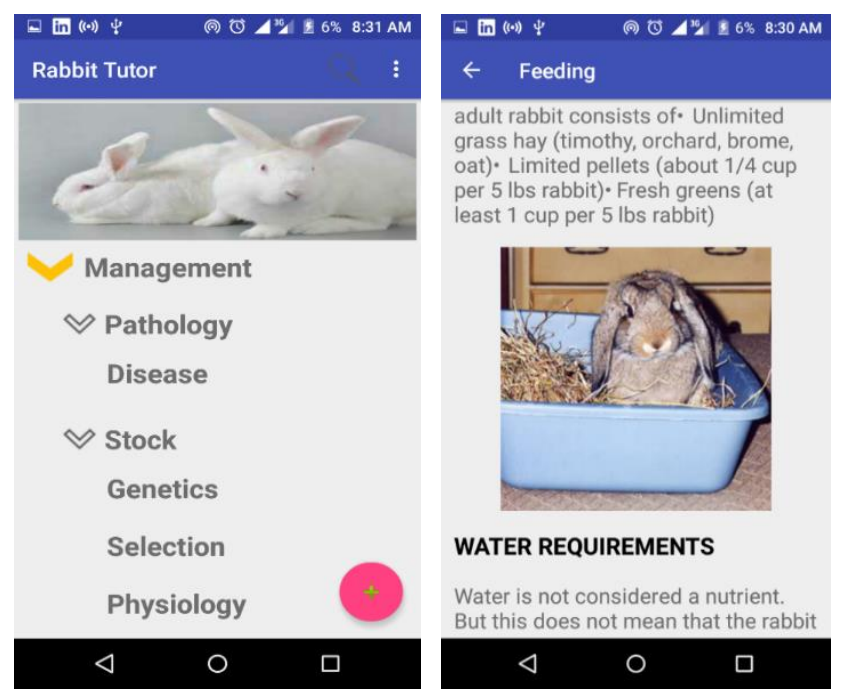

Fig. 10. Interfaces of Subclasses and Specific Subclass Information.
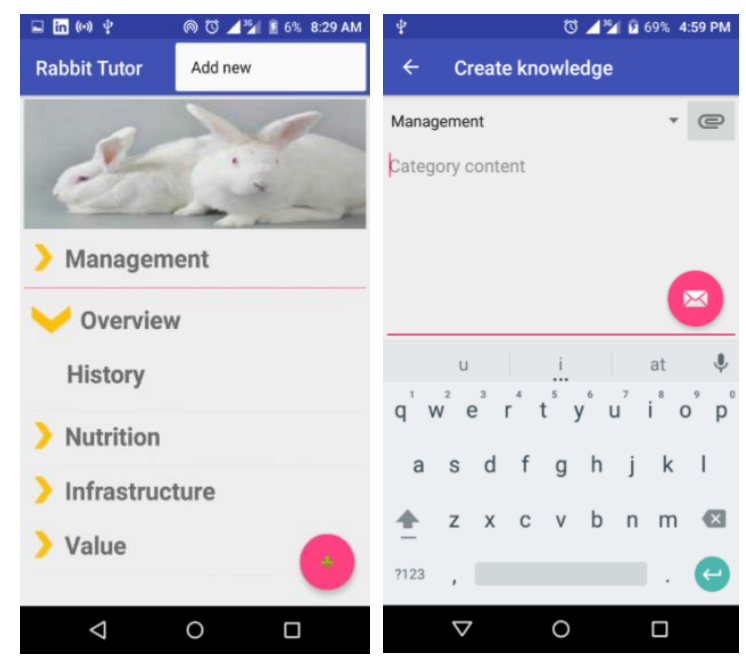

Fig. 11. Knowledge Inclusion Link and Interface.

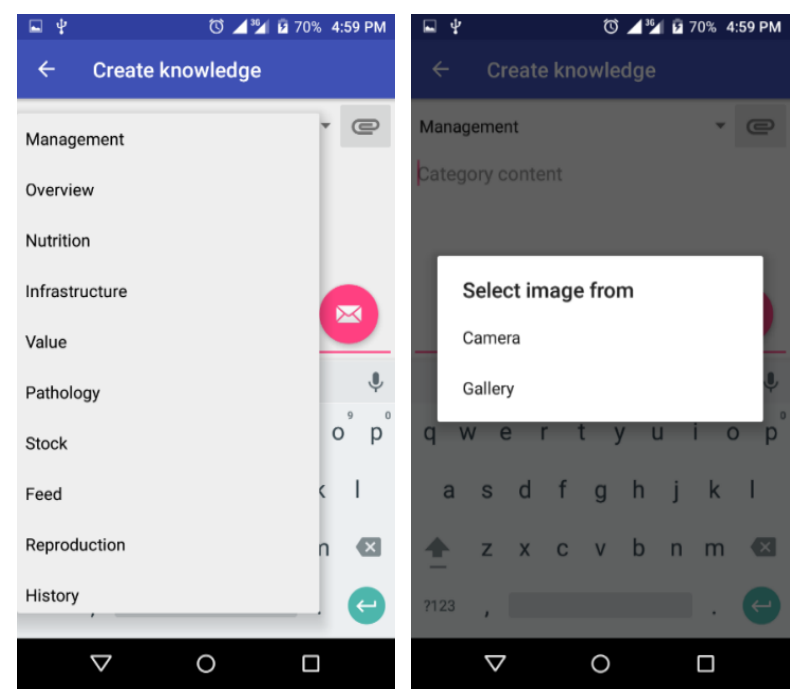

Fig. 12. Selecting Knowledge Subdomain and Images.

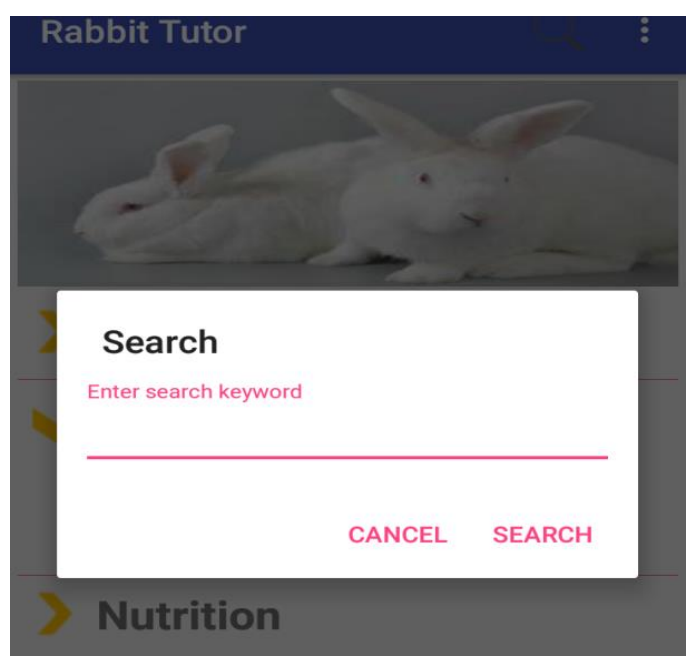

Fig. 13. Search Result and Specific Result Details.

\begin{tabular}{|c|c|}
\hline (ఠ) $\Lambda^{30} \square 1 \%$ 9:34 AM & 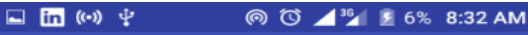 \\
\hline Search 'feed':11 & Disease \\
\hline $\begin{array}{l}\text { History } \\
\text { HISTORY OF RABBIT FARMING: }\end{array}$ & \multirow{7}{*}{$\begin{array}{l}\text { raDDISS. However, tne early contact } \\
\text { does confer relative immunity. } \\
\text { PHYSIOPATHOLOGY OF } \\
\text { DIARRHOEA OF COCCIDIAN } \\
\text { ORIGIN } \\
\text { The main symptom of intestinal } \\
\text { disease in young rabbits is diarrhoea. } \\
\text { Rabbit enteritis following } \\
\text { cocciodiosis has been studied with } \\
\text { reference to calves and human } \\
\text { infants, in whom episodes of } \\
\text { diarrhoea are essentially linked with } \\
\text { hydromineral perturbations. In calves } \\
\text { and infants diarrhoea seems to be } \\
\text { dominated by three main } \\
\text { phenomena. There is, of course, } \\
\text { considerable loss of faecal matter. } \\
\text { The usual impact on the metabolism } \\
\text { is extracellular dehydration and } \\
\text {. }\end{array}$} \\
\hline $\begin{array}{l}\text { Anatomy } \\
\text { ANATOMY:DIGESTIVE TRACT OF A }\end{array}$ & \\
\hline $\begin{array}{l}\text { Disease } \\
\text { DISEASES: It would be inappropriate }\end{array}$ & \\
\hline $\begin{array}{l}\text { Environment } \\
\text { RABBIT FARMING ENVIRONMENT: }\end{array}$ & \\
\hline $\begin{array}{l}\text { Kindling } \\
\text { KINDLING: The doe usually kindles }\end{array}$ & \\
\hline $\begin{array}{l}\text { Mating } \\
\text { MATING:Servicing is always done in }\end{array}$ & \\
\hline $\begin{array}{l}\text { Pregnancy } \\
\text { PREGNANCY: The only effective }\end{array}$ & \\
\hline 0 & 0 \\
\hline
\end{tabular}

Fig. 14. Search Result and Specific Result Details. 
TABLE I. RESUlt OF QuAlitative AsSESSMENT OF RAB-KAMS

\begin{tabular}{|l|l|}
\hline Metrics & Average Value (\%) \\
\hline Graphic User Interface & 85.2 \\
\hline User-friendliness & 92.7 \\
\hline Efficiency & 90.1 \\
\hline Reliability & 93.4 \\
\hline Cost & 81.6 \\
\hline
\end{tabular}

B. Qualitative Evaluation Result of the Developed Rab-KAMS

The qualitative evaluation of the performance of RabKAMS was conducted using a well-structured questionnaire with major focus on its graphic user interface, userfriendliness, cost, reliability and efficiency. A total of 50 copies of questionnaire were distributed to commercial rabbit farmers who have interacted with Rab-KAMS for at least 3 months. However, 46 copies of the questionnaire were returned representing a response rate of $92 \%$. The analysis of the responses obtained is summarized in Table 1.

The reliability of use of Rab-KAMS has the highest rated average value at $93.4 \%$ due to the quality of expert information used to develop the system. The user-friendliness is next and rated at an average of $92.7 \%$ because the system is easy to learn and use. The graphical user interface, rated at an average of $85.2 \%$, was developed using visual indicators, tool tips and icons to accommodate users with visual impairments. The efficiency of the system was rated at an average of $90.1 \%$ due to its high response time and lesser demand for the computational resources of the underlying hardware. It is also cost-effective, rated at an average of $81.6 \%$, saving the farmer the need to spend more money on professional training relating to RFP because the system is instruction-based with knowledge of several experts well-refined and incorporated wholly into its knowledge.

\section{CONCLUSION}

Sustainable rabbit farming and production requires consistent availability of adequate and concise information regarding its operations and methods to achieve success. Owing to this, it is important that sound knowledge be made readily available to prospective farmers without restrictions to avoid extinction of such noble practice. Challenges such as portability, network strength and coverage to access online repositories, cost of data, limited knowledge and knowledge rigidity have been resolved through the mobile-oriented rabbit production knowledge archiving and management system developed in this study. This study properly analyzed the various classes that were found to be pertinent to the successful production of rabbits, constructively categorized various subclasses under related classes and also represented these classes and their different relationships using ontology class diagram. Furthermore, Rab-KAMS was implemented on android operating system and was qualitatively evaluated based on users' review in terms of graphical user interface, user-friendliness, efficiency, reliability and cost. The results obtained show that Rab-KAMS is a flexible and modular system for tractable representation of processes, activities, objects and procedures involved in the production and farming of rabbits. However, future systems of this kind can implement the Rab-KAMS for other mobile operating systems like windows and iOS to enhance the universality of rabbit production knowledge archiving and management systems such as this. Knowledge of other animal production procedures less practiced nowadays can also be archived and managed in a similar version like the Rab-KAMS as a knowledge management proactive intervention.

\section{REFERENCES}

[1] Arisha and M. Ragab (2013). Knowledge Management and Measurement: A Critical Review. Journal of Knowledge Management, Volume 17 (6), 1-36.

[2] B. F. Irma and S. Rajiv (2010): Knowledge Management System and Processes. $2^{\text {nd }}$ ed.; M.E. Sharpe Inc., 80 Business Park Drive, Armonk, New York; pp. 1-369, 978-0-7656-2351-5.

[3] P. Maureen (2013): Web Archiving. DPC Technology Watch Report 2013, 1-45.

[4] L.B. Christine, S. Andrea and S. G. Milena (2018): Digital Data Archives as Knowledge Infrastructures: Mediating Data Sharing and Reuse. Journal of the Association for Information Science and Technology, pp. 1-35, https://arxiv.org/abs/1802.02689.

[5] E. Schweizerische (2009): Digital Archiving Policy; Federal Department of Home Affairs, Swiss Federal Archives, 3003 Bern, France, pp. 1-40.

[6] B. Christoph (2006). ReUse Cases: Supporting Knowledge Management and Reuse with Self-Organizing Use Case Maps, A Thesis in the Institute of Software Technology and Interactive Systems, Vienna University of Technology.

[7] J.K. Jillinda, M. Karen, L. Vander and L. J. Sandra (2000): Applying Corporate Knowledge Management Practices in Higher Education, Educause Quarterly, Volume 4, 28-33.

[8] G. P. Jane, A. Shireen, B. Neeru, G. Hashini Galhena, M. Ruth and M. Karim (2018). Managing Agricultural Research for Prosperity and Food Security in 2050: Comparison of Performance, Innovation Models and Prospects. The Open Agriculture Journal, vol. 12, 20-35.

[9] G. Babita, S.I. Lakshmi, J.E. Aronson (2000): Knowledge Management: Practices and Challenges. Industrial Management and Data Systems, 2000, Volume 100 (1), 17-21.

[10] Z. Yun, W. Lei and D. Yanqing (2016). Agricultural Information Dissemination using ICTs: A Review and Analysis of Information Dissemination Models in China, Information Processing in Agriculture 3(1), 17-29.

[11] G. John and G. Joann (2015): Defining Knowledge Management: Toward an applied compendium. Online Journal of Applied Knowledge Management, Volume 3 (1), 1-20.

[12] M. Mohamad and M.I. Gombe (2017). E-Agriculture revisited: a systematic literature review of theories, concept, practices, methods and future trends. University of Salford Manchester, http://usir.salford.ac.uk/43648/.

[13] L. Daiyi, K. Li, C. Xinrong, L. Daoliang, J. Laiqing, W. Kaiyi and C. Yingyi (2013): An ontology-based knowledge representation and implement method for crop cultivation standard. Mathematical and Computer Modelling, Volume 58, 466-473.

[14] A. Giovanni, M. Marco, P. Laura and P. Luca (2015): An Ontology for Historical Research Documents. Web Reasoning and Rule Systems; $9^{\text {th }}$ International Conference, RR 2015, Berlin, Germany.

[15] B. Alan (2017). Rural-urban Migration and Implications for Rural Production. Bio-based and Applied Economics, 6(3): 229-242.

[16] E.N. Mbah, C.I. Ezeano, C.I. and M.O. Agada (2016). Effects of RuralUrban Youth Migration in Farm Families in Benue State, Nigeria. Int. J. Agril. Res. Innov. \&Tech, Volume 6 (1), 14-20.

[17] U.O. Albert, O. Oghenesuvwe and O. Oghenebrorhie (2016). Impact of Rural-Urban Migration on Poultry Production in the Niger Delta Region, Nigeria. International Journal of Agricultural Science, Research and Technology in Extension and Education Systems, 6(1), pp. 13-20. 
[18] D.G. Peter, G. Kisan and N. Barnabé (2004): Rural-Urban Migration and Agricultural Productivity: The Case of Senegal. Agricultural Economics, Volume 33(1), 33-45.

[19] O.D. Oloruntola and S.O. Ayodele (2017). "Pawpaw Leaf Meal and Exo-enzyme in Rabbit Diet: Effect on Hematological and Serum Biochemical Indices": Asian Journal of Advances in Agricultural Research, 2(4), 1-8.

[20] S. Khashayar, Mohammed and H. Sajad (2014): "The Role of Information Technology in Agricultural Development": Journal of Novel Applied Sciences. 3(2), 203-205.

[21] S.A. Ugosor, A.O. Ochu and O.N. Agbulu (2016). Identification of breeding skills required by Farmers in Rabbit production for income generation in Benue State. Scholarly Journal of Agricultural Science, 2016; Volume 6(7), 204-210.

[22] S.I. Ume, C.I. Ezeano, T.C. Nwaneri and C. Eluagu (2017): Economics of Rabbit (Oryctolagus Cuniculus) Production in IVO Local Government of Area of Ebonyi State. International Journal of Research and Review, Volume 4(1), 126-135.

[23] W. Peng, Z. Fang-Wei, S. Hao-Yang, H. Jian-Hua and Z. Jin-Lan (2018): Visualizing the Academic Discipline of Knowledge Management, Sustainability, Volume 682 (10), pp. 1-28.

[24] S. Mohammed and D. Danciulescu (2018). Modern Interfaces for Knowledge Representation and Processing Systems Based on Markup Technologies, International Journal of Computers Communications \& Control, Volume 13(1), pp. 117-128.

[25] T.M. Fagbola, S.O. Olabiyisi and A.A. Adigun (2012). RROVT: A Proposed Visualization Tool for Semantic Web Technologies. Journal of Information Engineering and Applications, Volume 2(3): pp 7-25.

[26] S. Ruban, T. Kedar, P.R. Austin and S. Niriksha (2014): An OntologyBased Information Retrieval Model for Domesticated Plants: International Journal of Innovative Research in Computer and Communication Engineering, Volume 2(5), 207-213.

[27] P. Suresh, A.S. Mohamed and L. Jens (2014). Ontology Based Data Access and Integration for improving the Effectiveness of Farming in Nepal. IEEE WIC/ACM International Joint Conferences on Web Intelligence (WI) and Intelligent Agent Technologies (IAT), IEEE Computer Society, DOI: 10.1109/WI-IAT.2014.114.

[28] M. Aunur-Rofiq, S. Jean-Michel, N. Pascal, C. Brigitte and B. Patrice (2014): Ontology-based Model for Food Transformation Processes Application to Winemaking, In a book of proceedings, Communication in Computer and Information Science, pp. 1-15.

[29] H. Mutao and T. Yong (2015): A Centralized System for Managing, Archiving and Serving Scientific Data in Ecohydrological Research, in a book of proceedings of the 2 nd international conference on intelligent computing and cognitive informatics, pp. 1-10.

[30] X. Han (2018): KSR: A Semantic Representation of Knowledge Graph within a Novel Unsupervised Paradigm, IJCAI, arXiv:1608.07685v7, pp. $1-7$.

[31] S. Rashmi and S. Neha (2015): Knowledge Representation in Artificial Intelligence using Domain Knowledge and Reasoning Mechanism, International Journal of Scientific Engineering and Research (IJSER), pp. 17-20.
[32] F.J. Vijay and A. Sunitha (2015): Ontology based disaster prediction using Animals behavioral changes, Journal of Computation in Biosciences and Engineering, Volume 2 (3), pp. 1-6.

[33] K. Sabina and N. Leonids (2018): Choice of Knowledge Representation Model for Development of Knowledge Base: Possible Solutions, International Journal of Advanced Computer Science and Applications, Volume 9 (2), pp. 358-363.

[34] G. Didem, V.F. Aneta, E. Jad, K.M. Swarup, B. Ramamurthy, P.M. Anusha and F. Elena (2018): Knowledge Representation of Cyberphysical Systems for Monitoring Purpose; 51st CIRP Conference on Manufacturing Systems, Procedia, pp. 1-6.

[35] J. Sarika and M. Sanju (2014): Knowledge Representation with Ontology Tools \& Methodology, International Journal of Computer Applications, pp. 1-5.

[36] S. Aaron and V. Andreas (2018): Knowledge Representation of Requirements Documents using Natural Language Processing, CEURWS.org, Volume 2075, pp. 1-8.

[37] D. Marek, L. Steffen, S. Vojtěch and P. Dmitry (2018): Ontology visualization methods and tools: a survey of the state of the art. The Knowledge Engineering Review, Vol. 33, 10, 1-39.

[38] C. Ochs, J. Geller, M.A. Musen and Y. Perl (2017): Real time summarization and visualization of ontology change in protege. In Proceedings of the 3rd International Workshop on Visualization and Interaction for Ontologies and Linked Data (ISWC 2017), CEUR Workshop Proceedings 1947, 75-86. CEUR-WS.org.

[39] C. Ware (2012): Information Visualization: Perception for Design. Elsevier.

[40] S. Falconer (2010): OntoGraf Protege plugin. Place, http://protegewiki.stanford.edu/wiki/ OntoGraf (accessed 21 September 2018).

[41] P. Rathee and S.K. Malik (2018). Proposed UML Approach for Ontology Design and Representation: A Banking System Case Study. International Journal of Computer Sciences and Engineering, 6(6), 491499.

[42] C.G. Vicky, C. Qing and D. Wenjing (2012). Unified Modeling Language (UML) IT adoption - A holistic model of organizational capabilities perspective. Decision Support Systems, 54, 257-269.

[43] N. Ren and S.S. Chaudhry (2008): An Enterprise Knowledge Management System Based on the Use Case Model. In: Xu L.D., Tjoa A.M., Chaudhry S.S. (eds) Research and Practical Issues of Enterprise Information Systems II. IFIP International Federation for Information Processing, vol 255. Springer, Boston, MA.

[44] E. Eileen (2004): A Use-Case Model for a Knowledge Management System to Facilitate Disaster Relief Operations, A Ph.D Thesis in the Graduate School of Computer and Information Sciences, Nova Southeastern University.

[45] V. Nazaruks and J. Osis (2017): A Survey of Domain Knowledge Representation with Frames. In proceedings of the $12^{\text {th }}$ International Conference on Evaluation of Novel Approaches to Software Engineering, pp. 346-354, DOI: 10.5220/000638830346035. 